\section{JURNAL EKONOMI EFEKTIF}

ISSN : $2622-8882$, E-ISSN : 2622-9935

Jurnal Ekonomi Efektif, Vol. 3, No. 3, April 2021

@Prodi Manajemen Fakultas Ekonomi Universitas

Pamulang

\title{
PENGARUH PENEMPATAN KERJA TERHADAP PRESTASI KERJA KARYAWAN PADA PT. BERDIKARI PONDASI PERKASA DI JAKARTA PUSAT
}

\author{
Muhamad Abid \\ Universitas Pamulang, Tangerang Selatan, Banten, Indonesia \\ dosen02466@unpam.ac.id
}

Manuskrip: Mar-2021 Ditinjau: Mar-2021; Diterima: Mar-2021; Online: Apr-2021; Diterbitkan: Apr-2021

\begin{abstract}
ABSTRAK
Penelitian ini bertujuan untuk mengetahui pengaruh Penempatan Kerja terhadap Prestasi Kerja karyawan pada PT. Berdikari Pondasi Perkasa di Jakarta Pusat. Metode yang digunakan adalah explanatory research dengan sampel sebanyak 64 responden. Teknik analisis menggunakan analisis statistik dengan pengujian regresi, korelasi, determinasi dan uji hipotesis. Hasil penelitian ini variabel Penempatan Kerja diperoleh nilai rata-rata skor sebesar 3,748 dengan kriteria baik. Variabel Prestasi Kerja karyawan diperoleh nilai rata-rata skor sebesar 3,780 dengan kriteria baik. Penempatan Kerja berpengaruh positif dan signifikan terhadap Prestasi Kerja karyawan dengan nilai persamaan regresi $\mathrm{Y}=12,059+0,687 \mathrm{X}$, dan nilai koefisien korelasi 0,787 atau memiliki tingkat hubungan yang kuat dengan nilai determinasi 62,0\%. Uji hipotesis diperoleh signifikansi $0,000<0,05$.
\end{abstract}

\section{Kata Kunci: Penempatan Kerja, Prestasi Kerja Karyawan.}

\section{ABSTRACT}

This study aims to determine the effect of Job Placement on Employee Performance at PT. Berdikari Foundation Perkasa in Central Jakarta. The method used is explanatory research with a sample of 64 respondents. The analysis technique uses statistical analysis with regression testing, correlation, determination and hypothesis testing. The results of this study, the work placement variable obtained an average score of 3,748 with good criteria. Employee performance variable obtained an average score of 3,780 with good criteria. Job placement has a positive and significant effect on employee job performance with the regression equation $Y=12.059+0.687 X$, and a correlation coefficient value of 0.787 or having a strong level of relationship with a determination value of $62.0 \%$. Hypothesis testing obtained a significance of $0.000<0.05$.

Keywords: Work Placement, Employee Performance. 


\section{PENDAHULUAN}

\section{A. Latar Belakang Masalah}

Indonesia sebagai Negara berkembang sedang giat-giatnya melakukan pembangunan terutama pada sektor industri perekonomian,dan perdagangan. Ini dimaksudkan untuk meningkatkan taraf hidup dan kesejahtraan bangsa Indonesia sendiri.Sejalan dengan pembangunan itu banyak perusahaan yang tumbuh dan berkembang dengan harapan dapat menyerap tenaga kerja yang cukup banyak sehingga dapat mengurang pengangguran di bangsa ini.

Sumber daya manusia merupakan salah satu aset yang paling penting dalam perusahaan,karena sumber daya manusia secara aktif menggerakkan sumber daya manusia sebagai tenaga kerja merupakan faktor penentu dalam tujuan perusahaan yang hendak dicapai. Dalam hal ini manusia unsur utama dalam Organisasi merupakan faktor produksi yang harus mendapat perhatian utama berbeda dengan sumber daya atau faktor produksi lainnya dalam perusahaan. Didalam menjalankan tugas pekerjaan yang mana manusia mempunyai watak serta motivasi yang berbeda antara satu terhadap lainnya,maka tidak jarang dalam pelaksanaan tugas pekerjaannya kurang searah dan sesuai terhad apa yang direncanakan semula. Dengan demikian untuk menyatukan arah kegiatan tersebut diperlukan adanya suatu penempatan karyawan yang mendukung prestasi kerja.

Langkah awal dalam menghasilkan sumber daya manusia yang terampil dan handal, perlu adanya suatu perencanaan dalam menentukan karyawan yang akan mengisi pekerjaan yang ada dalam perusahaan yang bersangkutan. Keberhasilan dalam pengadaan tenaga kerja terletak pada ketepatan dalam penempatan karyawan, baik penempatan karyawan baru maupun karyawan lama pada possisi jabatan baru.

Proses penempatan merupakan suatu proses yang sangat menentukan dalam mendapatkan karyawan yang kompeten yang di butuhkan pada suatu lembaga, karena penempatan yang tepat dalam posisi jabatan yang tepat akan dapat membantu lembaga tersebut dalam mencapai tujuan yang di harapkan. Menurut Wilson Bangun (2012), penempatan (placement) berkaitan dengan penyesuaian kemampuan dan bakat seseorang dengan pekerjaan yang akan dikerjakannya. Suatu tugas manajer yang penting untuk menempatkan orang sesuai dengan pekerjaan yang tepat. Seseorang diberikan pekerjaan sesuai dengan pengetahuan, keterampilan dan kemampuan yang dimiliki sesuai dengan persyaratan pekerjaan. Kesalahan dalam menempatkan karyawan pada pekerjaan yang sesuai akan mendapatkan hasil yang kurang baik. Ketidaktelitian dalam hal ini bisa berakibat pada kurangnya semangat kerja yang berdampak pada rendahnya prestasi kerja dan tingginya tingkat turnover dan absensi pegawai.

Dengan demikian peran penempatan karyawan yang tepat merupakan bagian yang sangat penting dalam organisasi perusahaan.Apabila hasil yang dicapai sesuai yang direncanakan maka seorang pemimpin dalam menjalankan fungsinya disebut efektif. Maka hal ini didasari oleh pihak perusahaan dengan adanya seorang pemimpin dan ditunjang dengan penempatan karyawan mendukung pada pimpinan tidak melaksanakan fungsinya dengan baik dalam arti kurang efektif maka akibatnya prestasi kerja akan menurun.

Faktor-faktor yang mempengaruhi prestasi kerja Menurut Mangkunegara (2002:33) salah satunya adalah kemampuan, secara psikologis, kemampuan (ability) karyawan terdiri dan kemampuan potensi (IQ) dan kemampuan reality (knowledge + skill). Artinya karyawan yang memiliki IQ diatas rata-rata : (IQ 110 -120) dengan pendidikan yang memadai untuk jabatannya dan terampil dalam mengerjakan pekerjaan sehari- hari, maka ia akan lebih mudah mencapai Prestasi Kerja yang diharapkan. Oleh 
sebab itu karyawan perlu ditempatkan pada pekerjaan yang sesuai dengan keahlian.

Agar tercapainya suatu prestasi kerja yang baik maka tercapai efisiensi dan efektifitas dalam mengoptimalkan penggunaan tenaga kerja maka kemampuan karyawan yang diperlukan dapat diberikan pendidikan dan pelatihan pelatihan dalam hal pekerjaan, selain itu para karyawan diberikan balas jasa atau gaji yang sesuai dengan prestasi yang diberikan.

Berhasil atau tidaknya tujuan perusahaan tergantung kepada banyak faktor yang mempengarui karyawan untuk memberikan prestasi kerja yang baik, salah satu faktor adalah tergantung kepada ketepatan tempat dan posisi mereka bekerja.

Dalam melakukan observasi awal Penulis menemukan indikasi belum optimalnya Prestasi kerja karyawan, yaitu banyak karyawan yang tidak mencapai target yang diharapkan oleh Perusahaan. Wawancara yang dilakukan kepada Direktur HRD mengatakan bahwa "Masih banyak karyawan yang belum menguasi apa yang haru dikerjakan sehingga menyebabkan hasil kerja karyawan tidak sesuai dengan yang diharapkan".

Berdasarkan uraian latar belakang tersebut diatas penulis tertarik untuk melakukan penelitian dengan judul "Pengaruh Penempatan Karyawan Terhadap Prestasi Kerja Pada PT. Berdikari Pondasi Perkasa di Jakarta Pusat".

\section{B. Rumusan Masalah}

1. Bagaimana Penempatan Kerja pada PT. Berdikari Pondasi Perkasa di Jakarta Pusat?.

2. Bagaimana Prestasi Kerja karyawan pada PT. Berdikari Pondasi Perkasa di Jakarta Pusat?.

3. Adakah pengaruh antara Penempatan Kerja terhadap Prestasi Kerja karyawan pada PT. Berdikari Pondasi Perkasa di Jakarta Pusat?.

\section{Tujuan Penelitian}

1. Untuk mengetahui kondisi Penempatan Kerja pada PT. Berdikari Pondasi Perkasa di Jakarta Pusat.

2. Untuk mengetahui kondisi Prestasi Kerja karyawan pada PT. Berdikari Pondasi Perkasa di Jakarta Pusat.

3. Untuk mengetahui pengaruh antara Penempatan Kerja terhadap Prestasi Kerja karyawan pada PT. Berdikari Pondasi Perkasa di Jakarta Pusat.

\section{METODE PENELITIAN}

\section{Populasi}

Populasi dalam penelitian ini berjumlah 64 responden PT. Berdikari Pondasi Perkasa di Jakarta Pusat

\section{Sampel}

Teknik pengambilan sampling dalam penelitian ini adalah sampel jenuh, dimana semua anggota populasi dijadikan sebagai sampel. Dengan demikian sampel dalam penelitian ini sampel yang digunakan berjumlah 64 responden.

\section{Jenis Penelitian}

Jenis penelitian yang dipakai adalah asosiatif, dimana tujuannya adalah untuk mengetahui atau mencari keterhubungan antara variabel independen terhadap variabel dependennya

\section{Metode Analisis Data}

Dalam menganalisis data digunakan uji validitas, uji reliabilitas, analisis regresi linier sederhana, analisis koefisien korelasi, analisis koefisien determinasi dan pengujian 
hipotesis.

\section{HASIL PENELITIAN DAN PEMBAHASAN}

\section{Analisis Deskriptif}

Pada pengujian ini digunakan untuk mengetahui skor minimum dan maksimum skor tertinggi, ratting score dan standar deviasi dari masing-masing variabel. Adapun hasilnya sebagai berikut:

Tabel 1. Hasil Analisis Descriptive Statistics

Descriptive Statistics

\begin{tabular}{lr|r|r|r|r} 
& N & \multicolumn{1}{c|}{ Minimum } & Maximum & \multicolumn{1}{c}{ Mean } & \multicolumn{1}{c}{ Std. Deviation } \\
\hline Penempatan Kerja (X) & 80 & 28 & 44 & 34.00 & 4.016 \\
\hline Prestasi Kerja Karyawan (Y) & 80 & 29 & 49 & 38.11 & 4.183 \\
\hline Valid N (listwise) & 80 & & & & \\
\hline
\end{tabular}

Penempatan Kerja diperoleh varians minimum sebesar 29 dan varians maximum 49 dengan ratting score sebesar 3,748 dengan standar deviasi 4,687. Skor ini termasuk pada rentang sakala 3,40-4,19 dengan kriteria baik atau setuju.

Prestasi Kerja karyawan diperoleh varians minimum sebesar 29 dan varians maximum 48 dengan ratting score sebesar 3,780 dengan standar deviasi 4,087. Skor ini termasuk pada rentang sakala 3,40 - 4,19 dengan kriteria baik atau setuju.

\section{Analisis Verifikatif.}

Pada analisis ini dimaksudkan untuk mengetahui pengaruh variabel independen terhadap variabel dependen. Adapun hasil pengujian sebagai berikut:

\section{a. Analisis Regresi Linier Sederhana}

Uji regresi ini dimaksudkan untuk mengetahui perubahan variabel dependen jika variabel independen mengalami perubahan. Adapun hasil pengujiannya sebagai berikut:

Tabel 2. Hasil Pengujian Regresi Linier Sederhana

\section{Coefficients $^{\mathrm{a}}$}

Unstandardized

Coefficients

\begin{tabular}{lr|r|r|r|c} 
Model & \multicolumn{1}{c}{ B } & Std. Error & Beta & \multicolumn{1}{c}{ t } & \multicolumn{1}{c}{ Sig. } \\
\hline 1 (Constant) & 12.059 & 2.578 & & 4.677 & .000 \\
\hline Penempatan Kerja $(\mathrm{X})$ & .687 & .068 & .787 & 10.059 & .000 \\
\hline
\end{tabular}

Berdasarkan hasil pengujian pada tabel di atas, diperoleh persamaan regresi $\mathrm{Y}$ $=12,059+0,687 \mathrm{X}$. Dari persamaan tersebut dijelaskan sebagai berikut:

1) Konstanta sebesar 12,059 diartikan jika Penempatan Kerja tidak ada, maka telah terdapat nilai Prestasi Kerja karyawan sebesar 12,059 point.

2) Koefisien regresi Penempatan Kerja sebesar 0,687, angka ini positif artinya setiap ada peningkatan Penempatan Kerja sebesar 0,687 point maka Prestasi Kerja karyawan juga akan mengalami peningkatan sebesar 0,687 point.

\section{b. Analisis Koefisien Korelasi}

Analisis koefisien korelasi dimaksudkan untuk mengetahui tingkat kekuatan hubungan dari variabel independen terhadap variabel dependen. Adapun hasil pengujian sebagai berikut: 
Tabel 3. Hasil Pengujian Koefisien Korelasi Penempatan Kerja Terhadap Prestasi Kerja Karyawan..

Correlations $^{\mathrm{b}}$

\begin{tabular}{llr|r} 
& & \multicolumn{2}{c}{$\begin{array}{c}\text { Kinerja } \\
\text { Karyawan (Y) }\end{array}$} \\
\hline Penempatan Kerja (X) & Pearson Correlation & 1 & $.767^{* *}$ \\
\cline { 2 - 4 } & Sig. (2-tailed) & & .000 \\
\hline Prestasi Kerja Karyawan (Y) & Pearson Correlation & $.767^{* *}$ & 1 \\
\cline { 2 - 4 } & Sig. (2-tailed) & .000 & \\
\hline
\end{tabular}

Berdasarkan hasil pengujian diperoleh nilai korelasi sebesar 0,787 artinya Penempatan Kerja memiliki hubungan yang kuat terhadap Prestasi Kerja karyawan.

\section{c. Analisis Koefisien Determinasi}

Analisis koefisien determinasi dimaksudkan untuk mengetahui besarnya persentase pengaruh dari variabel independen terhadap variabel dependen. Adapun hasil pengujian sebagai berikut:

Tabel 4. Hasil Pengujian Koefisien Determinasi Penempatan Kerja Terhadap Prestasi Kerja Karyawan.

Model Summary

\begin{tabular}{lr|r|rrr} 
& & & \multicolumn{2}{c}{$\begin{array}{c}\text { Std. Error of the } \\
\text { Estimate }\end{array}$} \\
\hline 1 & R & R Square & Adjusted R Square & .614 & 2.540 \\
\hline
\end{tabular}

Berdasarkan hasil pengujian diperoleh nilai determinasi sebesar 0,620 artinya Penempatan Kerja memiliki kontribusi pengaruh sebesar 62,0\% terhadap Prestasi Kerja karyawan, sedangkan sisanya sebesar $38,0 \%$ dipengaruhi oleh faktor lain yang tidak dilakukan penelitian.

\section{d. Uji Hipotesis}

Pengujian hipotesis dengan uji t digunakan untuk mengetahui hipotesis mana yang diterima. Rumusan hipotesis: Terdapat pengaruh yang signifikan antara Penempatan Kerja terhadap Prestasi Kerja karyawan.

Tabel 5. Hasil Uji Hipotesis Penempatan Kerja Terhadap Prestasi Kerja Karyawan.

\section{Coefficients $^{\mathrm{a}}$}

\begin{tabular}{|c|c|c|c|c|c|}
\hline \multirow[b]{2}{*}{ Model } & \multicolumn{2}{|c|}{$\begin{array}{l}\text { Unstandardized } \\
\text { Coefficients }\end{array}$} & \multirow{2}{*}{$\begin{array}{c}\text { Standardized } \\
\text { Coefficients } \\
\text { Beta }\end{array}$} & \multirow[t]{2}{*}{$\mathrm{t}$} & \multirow[t]{2}{*}{ Sig. } \\
\hline & $\mathrm{B}$ & Std. Error & & & \\
\hline 1 (Constant) & 12.059 & 2.578 & & 4.677 & .000 \\
\hline Penempatan Kerja (X) & .687 & .068 & .787 & 10.059 & .000 \\
\hline
\end{tabular}

Berdasarkan hasil pengujian pada tabel di atas, diperoleh nilai t hitung $>\mathrm{t}$ tabel atau $(10,059>1,999)$, dengan demikian hipotesis yang diajukan bahwa terdapat pengaruh yang signifikan atara Penempatan Kerja terhadap Prestasi Kerja karyawan diterima.

\section{PEMBAHASAN HASIL PENELITIAN}

\section{Kondisi Jawaban Responden Variabel Penempatan Kerja}

Berdasarkan jawaban responden, variabel Penempatan Kerja diperoleh ratting score sebesar 3,748 berada di rentang skala 3,40 - 4,19 dengan kriteria baik atau setuju. 


\section{Kondisi Jawaban Responden Variabel Prestasi Kerja Karyawan}

Berdasarkan jawaban responden, variabel Prestasi Kerja karyawan diperoleh ratting score sebesar 3,780 berada di rentang skala 3,40-4,19 dengan kriteria baik atau setuju.

\section{Pengaruh Penempatan Kerja Terhadap Prestasi Kerja Karyawan}

Penempatan Kerja berpengaruh signifikan terhadap Prestasi Kerja karyawan dengan persamaan regresi $\mathrm{Y}=12,059+0,687 \mathrm{X}$, nilai korelasi sebesar 0,787 atau memiliki hubungan yang kuat dengan kontribusi pengaruh sebesar $62,0 \%$. Pengujian hipotesis diperoleh nilai t hitung $>\mathrm{t}$ tabel atau $(10,059>1,999)$. Dengan demikian hipotesis yang diajukan bahwa terdapat berpengaruh signifikan antara Penempatan Kerja terhadap Prestasi Kerja karyawan diterima.

\section{V.PENUTUP}

\section{Kesimpulan}

a. Variabel Penempatan Kerja diperoleh ratting score sebesar 3,748 berada di rentang skala 3,40-4,19 dengan kriteria baik atau setuju.

b. Variabel Prestasi Kerja karyawan diperoleh ratting score sebesar 3,780 berada di rentang skala 3,40 - 4,19 dengan kriteria baik atau setuju.

c. Penempatan Kerja berpengaruh signifikan terhadap Prestasi Kerja karyawan dengan persamaan regresi $\mathrm{Y}=12,059+0,687 \mathrm{X}$, nilai korelasi sebesar 0,787 atau kuat dan kontribusi pengaruh sebesar $62,0 \%$ sedangkan sisanya sebesar 38,0\% dipengaruhi faktor lain. Uji hipotesis diperoleh nilai $t$ hitung $>t$ tabel atau $(10,059>1,999)$.

\section{Saran}

a. Dari hasil analisis jawaban Kuesioner, disarankan agar Perusahaan lebih meningkatkan karyawan dalam kemampuan menguasai peralatan dan perangkat kerja

b. Dari hasil analisis jawaban Kuesioner, disarankan agar Perusahaan lebih meningkatkan prestasi kerja karyawan agar lebih bertanggung jawab memanfaat kan waktu untuk menyelesaikan tugas di kantor.

\section{DAFTAR PUSTAKA}

Abdullah, M (2014) Manajemen dan Evaluasi Prestasi Kerja Karyawan, Yogyakarta: Penerbit Aswaja Pressindo.

Agus Dharma. 2014. Manajemen Prestasi Kerja. Jakarta : Rajawali Pers.

Algifari. (2015). “Analisis Regresi untuk Bisnis dan Ekonomi”. Yogyakarta: BPFE.

Anwar Prabu. 2002. Manajemen Sumber Daya Manusia Perusahaan. Bandung : PT. Remaja Rosdakarya.

Arikunto, Suharsimi (2014). "Prosedur Penelitian Suatu Pendekatan Praktek". Jakarta: Rineka Cipta.

Bangun, Wilson. 2012. Manajemen Sumber Daya Manusia. Bandung : Erlangga.

Bejo Siswanto (2013) Manajemen Tenaga Kerja Rancangan dalam Pendayagunaan dan Pengembangan Unsur Tenaga Kerja”, Bandung: Sinar Baru.

Dessler, G. (2006.) Manajemen Sumber Daya Manusia (Jilid II). Jakarta: Indeks.

Dessler, Garry. 2007. Manajemen Sumber Daya Manusia Edisi Kesepuluh. Klaten : PT. Indeks.

Edi Sutrisno (2016). Manajemen Sumber Daya Manusia. Jakarta: Prenadamedia Group.

Edwin B. Flippo. 2006. Manajemen Personalia. Jakarta : Erlangga.

George Terry R \& Rue, Leslie W. Rue (2016) Dasar-Dasar Manajemen, Jakarta Bumi 
Aksara.

Gerry Dessler (2016) Human Resources Management, Prenticehall, London: International Inc.

Handoko (2016) Manajemen Personalia dan Sumberdaya Manusia. Yogyakarta: BPFE.

Hasibuan, Malayu S.P. (2016). Manajemen Sumber Daya Manusia. Edisi Revisi. Jakarta: PT Bumi Aksara.

Heidjrachman dan Suad Husnan, 2002, Manajemen Personalia, edisi kelima, cetakan kesepuluh. Penerbit : BPFE, Yogyakarta.

Husein Umar. 2003. Desain Penelitian MSDM dan Perilaku Karyawan, Seri Desain Penelitian Bisnis - No 1. Jakarta : PT Rajagrafindo Persada.

Imam Ghozali (2017). "Aplikasi Analisis Multivariate Dengan Program SPSS”. Edisi Kelima. Semarang: Badan Penerbit Undip.

Istijanto (2014) "Riset Sumber Daya Manusia". Jakarta: PT. Gramedia Pustaka

Jasmani, J., \& Sunarsi, D. (2020). The Influence of Product Mix, Promotion Mix and Brand Image on Consumer Purchasing Decisions of Sari Roti Products in South Tangerang. PINISI Discretion Review, 1(1), 165-174.

Jusuf Soewadji. 2011. Pengantar Metodologi Penelitian. Jakarta: Mitra Wacana Media. Kharis, Ismu Fadli (2011). "Studi Mengenai Impulse Buying dalam Penjualan Luthans Fred (2014) Organizational Behavior, Ney York: McGraw-Hill, New York.

Mangkunegara, Prabu Anwar. (2016). Evaluasi Prestasi Kerja SDM. Cetakan ke tujuh, PT Refika Aditama: Bandung.

Marihot T. E Hariandja. 2005. Manajemen Sumber Daya Manusia. Jakarta : PT. Gramedia Widiasarana Indonesia.

Mathis Robert L. dan Jacson.John H 2006. Human Resource Management, alih bahasa. Jakarta: Salemba Empat.

Panggabean, S., Mutiara. 2004. Manajemen Sumber Daya Manusia. Bogor : Ghalia Indonesia.

Rao, Purba, (2012). "Measuring Consumer Perceptions Through Factor Analysis", The Asian.

Robbins, P.S, \& Judge, A.T. (2003). Organizational Behavior. Jakarta: Salemba Empat.

Samsudin, Sadili. 2006. Manajemen Sumber Daya Manusia. Bandung : Pustaka Setia.

Santoso, Singgih (2015). "Menguasai Statistik Multivariat". Jakarta: PT Elex Media Komputindo.

Sedarmayanti (2016) Manajemen Sumber Daya Manusia, Reformasi Birokrasi dan Manajemen Karyawan Negeri Sipil, Cetakan Kelima, Bandung: PT Refika Aditama.

Siagian, Sondang P. 2003. Manajemen Sumber Daya Manusia. Jakarta : PT. Bumi Aksara. Sudjana (2014) "Metode Statistika", Bandung: Tarsido.

Sugiyono (2017), "Metode Penelitian Administrasi : dilengkapi dengan Metode R \& D". Bandung: Alfabeta.

Suhartanto (2014). "Metode Riset Pemasaran". Bandung: Alfabeta

Suwatno 2003.Azas-azas Manajemen Sumber Daya Manusia. Bandung: Suci Press.

Triswanto, Sugeng D. 2010. Trik Menulis Skripsi dan Menghadapi Presentasi Beba. Stres. Tugu Publisher.

Veithzal Rivai (2015) Manajemen Sumber Daya Manusia Untuk Perusahaan, Jakarta: Raja Grafindo Persada.

Wibowo (2015) Manajemen Prestasi Kerja, Jakarta: PT. Raja Grafindo Persada. 